\title{
Review
}

\section{Neuromyogenic properties of the internal anal sphincter: therapeutic rationale for anal fissures}

\begin{abstract}
Summary
Lateral sphincterotomy diminishes internal anal sphincter hypertonia and thereby reduces anal canal pressure. This improves anal mucosal blood flow and promotes the healing of anal fissures. However, sphincterotomy can be associated with long term disturbances of sphincter function. The optimal treatment for an anal fissure is to induce a temporary reduction of anal canal resting pressure to allow healing of the fissure without permanently disrupting normal sphincter function. Broader understanding of the intrinsic mechanisms controlling smooth muscle contraction has allowed pharmacological manipulation of anal sphincter tone. We performed an initial Medline literature search to identify all articles concerning "internal anal sphincter" and "anal fissures". This review is based on these articles and on additional publications obtained by manual cross referencing. Internal anal smooth muscle relaxation can be inhibited by stimulation of nonadrenergic non-cholinergic enteric neurones, parasympathetic muscarinic receptors, or sympathetic $\beta$ adrenoceptors, and by inhibition of calcium entry into the cell. Sphincter contraction depends on an increase in cytoplasmic calcium and is enhanced by sympathetic $\alpha$ adrenergic stimulation. Currently, the most commonly used pharmacological agent in the treatment of anal fissures is topical glyceryl trinitrate, a nitric oxide donor. Alternative agents that exhibit a similar effect via membrane $\mathrm{Ca}^{2+}$ channels, muscarinic receptors, and $\alpha$ or $\beta$ adrenoceptors are also likely to have a therapeutic potential in treating anal fissures.
\end{abstract}

\section{Introduction}

Motility of a particular gut segment depends substantially on its extrinsic and intrinsic innervation. The extrinsic innervation is provided by preganglionic parasympathetic nerves and postganglionic sympathetic nerves which constitute the autonomic nervous system. Primary afferent neurones through which visceral impulses are conducted into the central nervous system effect reflex connections with preganglionic visceral efferent neurones. Functionally and anatomically they are related to the autonomic nervous system. Enteric nerves provide the intrinsic innervation. The anal sphincter complex, which controls defecation, consists of an inner ring of smooth muscle (the internal anal sphincter (IAS)) and an outer ring of skeletal muscle (the external anal sphincter (EAS)). The IAS is an involuntary muscle that maintains anal tone. It is normally in a state of tonic contraction due partly to the intrinsic myogenic properties of the smooth muscle and partly to extrinsic neural influences. ${ }^{12}$ The EAS is a voluntary fatigable muscle supplied by a somatic nerve that provides short term augmentation of anal pressure to postpone defecation.

There has been much recent clinical interest in the pharmacological manipulation of internal anal sphincter muscle tone based on the understanding of the intrinsic mechanisms of smooth muscle contraction and of the complex neural control of sphincter motility.
This review relates factors that modulate IAS tone to the pharmacological actions of therapies advocated for the treatment of anal fissures.

\section{Autonomic transmitters and pharmacology}

The autonomic nervous system anatomically comprises the craniosacral parasympathetic and thoracolumbar sympathetic components and, with the enteric nervous system, constitutes the efferent innervation of every body tissue except skeletal muscle. ${ }^{34}$ Autonomic nerves are predominately efferent but are associated with sensory visceral afferent fibres.

The original classification of the autonomic nerves, as devised by Dale, ${ }^{5}$ was based on the release of the primary transmitters acetylcholine and noradrenaline. Those neurones that synthesise and release acetylcholine are termed "cholinergic". These include almost all preganglionic efferent fibres leaving the central nervous system, all parasympathetic postganglionic, and a few sympathetic postganglionic fibres. Neurones that release noradrenaline are termed "adrenergic" or more accurately "noradrenergic", and include most postganglionic sympathetic fibres. It is now known that there are many different transmitters in autonomic neurones including purines,${ }^{6}$ peptides, ${ }^{7}$ and nitric oxide.

Cholinergic receptor subtypes, known as "muscarinic" and "nicotinic", were named after the alkaloids originally used in their identification. Dale noted that the cholinergic action of muscarine, when directly applied to autonomic effector tissues, was mediated by receptors at the effector cells and not by those in the ganglia. Nicotine, by contrast, was found to stimulate autonomic ganglia. Noradrenergic receptors are simpler to define in terms of their response to certain catecholamines and are therefore known as adrenoceptors. Ahlquist (1948) hypothesised that catecholamines act via two distinct receptors, $\alpha$ or $\beta$, and this was confirmed with the use of specific antagonists. In most smooth muscles $\alpha$ effects are excitatory and $\beta$ effects are inhibitory; phenoxybenzamine and phentolamine block $\alpha$ receptors and $\beta$ receptors are blocked by propanolol.

Adrenoceptors are further subclassified according to their preferential selective response to agonists and antagonists. The subtypes of $\alpha$ receptors have been identified with radiolabelled antagonists that distinguish between $\alpha_{1}$ and $\alpha_{2}$ receptors; for example prazocin antagonises $\alpha_{1}$ receptors, yohimbine antagonises $\alpha_{2}$ receptors, and dihydroergocryptine antagonises both $\alpha_{1}$ and $\alpha_{2}$ receptors. The intracellular effect of $\alpha_{1}$ receptor stimulation is mediated via an increase in inositol-1,4,5- trisphosphate $\left(\mathrm{IP}_{3}\right)$ but $\alpha_{2}$ receptor effects are mediated via a decrease in cyclic adenine-3'5'-

Abbreviations used in this paper: IAS, internal anal sphincter; EAS, external anal sphincter; NANC, non-adrenergic non-cholinergic; RAIR, rectoanal inhibitory reflex; 5-HT,

5-hydroxytryptamine; ATP, adenosine triphosphate; VIP, vasoactive intestinal peptide; $\mathrm{NO}$, nitric oxide; $\mathrm{NADPH}$, nicotinamide adenine dinucleotide phosphate; $\mathrm{Ca}^{2+}$, calcium ion; HIV, human immunodeficiency virus; GTN, glyceryl trinitrate; BoNT/A, botulinum neurotoxin type A; DMPP, dimethylphenylpiperazinium; ISDN, isosorbide dinitrate. 
monophosphate (cAMP). $\beta_{1}$ and $\beta_{2}$ receptors are defined by their affinities for adrenaline and noradrenaline, $\beta_{1}$ receptors having equal affinity for both agents but $\beta_{2}$ receptors have a higher affinity for adrenaline and respond to isoprenaline. The intracellular effect of $\beta$ receptor stimulation is mediated via an increase in cAMP. There are more divisions of adrenoceptor subtypes, and in the gut they have roles in secretion and motility. $\alpha_{1}$ Adrenoceptors are located postjunctionally on smooth muscle cells and intrinsic neurones while $\alpha_{2}$ adrenoceptors may be present both pre- and postsynaptically. $\beta_{1}$ and $\beta_{2}$ Adrenoreceptors are found mainly on smooth muscle cells but the former may be present on enteric neurones. ${ }^{8}$

\section{Nervous control of the internal anal sphincter}

The IAS receives its sympathetic innervation from the hypogastric pelvic plexuses. Parasympathetic innervation is from the first, second, and third sacral segments via the pelvic plexus. ${ }^{9}$ There seems to be some continuous excitatory sympathetic activity contributing to IAS tone but the precise interactions of the parasympathetic and enteric neurones are still poorly defined. Furthermore, there is a myogenic component which contributes to normal IAS basal tone. ${ }^{11011}$

\section{IN VIVO STUDIES}

Most of the work investigating the adrenergic contribution to IAS resting tone has been based on ideas introduced by Gaskell. In 1920 he suggested that the sympathetic nerves were excitatory and the parasympathetic inhibitory to the sphincter. ${ }^{12}$ Investigations on anaesthetised dogs a decade later confirmed Gaskell's initial ideas. ${ }^{13}$ In these experiments electrical stimulation of the lumbar sympathetic trunks and hypogastric nerves resulted in contraction of the IAS. It was concluded that the IAS received some motor innervation through the lumbar sympathetic outflow. Clinical significance of these observations was given by Rankin and Learmonth when they performed a limited sympathectomy to treat Hirschsprung's disease and certain types of constipation. ${ }^{14}$ In a young anaesthetised woman, stimulation of the peripheral end of the cut presacral nerves (preganglionic sympathetic nerves which divide into the hypogastric nerves) resulted in "strong clonic contractions of the sphincter followed by several weaker clonic contractions". These findings were the subjective comments of a surgical assistant with his gloved finger in the anal canal. ${ }^{15}$

In 1968 Shepherd and Wright investigated three normal subjects and 11 patients with Hirschsprung's disease or acquired sigmoid megacolon. ${ }^{15}$ They were unable to obtain simple or clonic contractions of the IAS with presacral nerve stimulation, as reported by Rankin and Learmonth. ${ }^{14}$ Instead they demonstrated clear inhibition of the sphincter with presacral nerve stimulation in all cases but were unable to explain either the mechanism or the neurotransmitter involved.

Electrical stimulation of the hypogastric nerves produced consistent contractile responses in animal studies. Carlstedt and colleagues observed IAS contraction in cats, ${ }^{16}$ and similar contractile responses were reported in dogs ${ }^{17}$ and in opossums. ${ }^{18}$ However, in a recent study in human subjects, Lubowski et al consistently obtained decreases in IAS tone in anaesthetised patients that were reproducible using a range of stimulation frequencies and intensities. ${ }^{19}$ They suggested that this effect was mediated through inhibitory $\beta$ adrenergic fibres.

Frenckner and Ihre examined the influence of the autonomic nerves on the IAS in humans ${ }^{1}$ by comparing anal canal pressure in patients after a high or low spinal anaesthetic, or bilateral pudendal nerve blocks. ${ }^{10}$ These inhibit respectively autonomic and somatic supply to the sphincter complex, the parasympathetic and somatic supply, and the somatic motor nerve supply to the external sphincter muscle. They demonstrated a decrease in anal canal pressure of $32 \mathrm{~mm} \mathrm{Hg}$ with high spinal anaesthesia but only about $10 \mathrm{~mm} \mathrm{Hg}$ with low spinal or pudendal nerve block. These findings reaffirm the theory that, at rest, there is tonic excitatory sympathetic discharge to the IAS. The contribution of the parasympathetic supply is not as significant.

Kerremans and Penninckx studied the physiological responses of the IAS in cats to various pharmacological agents. Adrenergic stimulation was performed using successive intravenous administration of adrenaline, noradrenaline, and isoprenaline, while phenoxybenzamine and propanolol were used as $\alpha$ and $\beta$ adrenoceptor antagonists, respectively. ${ }^{2021}$ Pressure recordings were made using micro-balloons placed in the rectum and anal canal; simultaneous measurements of electrical activity in the internal sphincter and rectum were also obtained. They demonstrated two types of pressure waves in the normal anal canal: "anal pressure waves" and "intestinal-like pressure waves". The anal pressure waves are phasic contractions occurring at a frequency of 8-30/minute. The intestinallike pressure waves are intermittent changes in the baseline pressure occurring at a rate of $2-5 /$ minute and usually lasting more than 10 seconds. They also showed that the anal pressure wave frequency and the level of the baseline pressure were increased by administration of adrenaline and noradrenaline through activity of excitatory $\alpha$ adrenoceptors. Attempts at defining the precise regulatory role of $\beta$ receptors were variable: an inhibitory effect was observed in $7 / 16$ stimulations with isoprenaline after $\alpha$ receptor blockade, implying that $\beta$ receptor stimulation has an inhibitory action on basal IAS tone.

In 1990 Yamato and Rattan published their findings on the role of $\alpha$ receptor subtypes based on clinical anorectal physiological measurements in anaesthetised opossums. ${ }^{22}$ Pancuronium bromide was used to inhibit the external sphincter while the resting pressure in the anal canal, representing IAS tone, was measured by a seven channel catheter assembly. They demonstrated that the $\alpha_{1}$ agonist phenylephrine caused a dose dependent rise in resting IAS pressure, with the more proximal part of the anal canal producing a significantly higher response than the distal part. This response was antagonised by prazocin, an $\alpha_{1}$ antagonist. It was not modified by the neurotoxin tetrodotoxin, supporting the concept that $\alpha_{1}$ adrenoceptors reside on smooth muscle cells. Clonidine, an $\alpha_{2}$ agonist, caused almost complete inhibition of IAS relaxation in response to rectal balloon distension; this response was antagonised by yohimbine. The site of action of clonidine was suggested to be proximal to the neuromuscular junction. These findings imply that activation of $\alpha_{1}$ adrenoceptors exerts primarily excitatory effects on the IAS smooth muscle, and activation of $\alpha_{2}$ adrenoceptors exerts an inhibitory modulatory action on the rectoanal inhibitory reflex causing suppression of reflex mediated IAS relaxation.

\section{IN VITRO STUDIES}

Parks et al (1969) described the effects of noradrenaline, adrenaline, isoprenaline, acetylcholine, and nicotine on muscle strips obtained from the upper and lower parts of the human IAS. ${ }^{23}$ Noradrenaline caused contraction of both parts, but caused relaxation when given after exposure of the muscle strip to phenoxybenzamine, an $\alpha$ receptor antagonist. This relaxation was attributed to stimulation of residual $\beta$ receptors as this effect could be counteracted by pronethalol (a $\beta$ receptor antagonist). Isoprenaline caused relaxation of both parts of the sphincter which was inhibited by pronethalol. The actions of adrenaline on the lower IAS muscle strips were complementary to these 
observations as low concentrations produced relaxation by preferential stimulation of $\beta$ receptors and higher concentrations produced contractions by successive recruitment of $\alpha$ receptors. Pronethalol antagonised relaxation and allowed a contraction to occur with a lower concentration while phenoxybenzamine prevented the contraction and allowed relaxation. Fewer conclusions could be drawn about the action of nicotine and acetylcholine. Although nicotine produced relaxation of strips from the upper part of the IAS, it had no effect on the lower part and the mechanism of action could not be clarified from the data available. Acetylcholine induced contractions in most muscle strips from the upper part of the sphincter whereas the lower part of the IAS was relatively insensitive.

Friedmann made similar observations when investigating the actions of catecholamines and nicotine on human isolated IAS muscle strips. ${ }^{24}$ Contractions occurred in both the proximal and distal parts of the IAS with noradrenaline whereas there was either contraction or relaxation with adrenaline, and only relaxation with isoprenaline. Nicotine usually caused muscle relaxation whereas dimethylphenylpiperazinium (DMPP), a nicotinic stimulant, caused contraction. This discrepancy was thought to be due to the differing molecular sizes of the drugs; nicotine released noradrenaline close to $\beta$ adrenoceptors and DMPP released noradrenaline near $\alpha$ adrenoceptors. Both proximal and distal segments of the anal sphincter were relatively unresponsive to acetylcholine; only minor contractions or relaxations occurred, despite the addition of the anticholinesterase physostigmine.

By 1975 there had been no uniform consensus regarding the action of acetylcholine on IAS tone. ${ }^{23-25}$ Burleigh and colleagues sought to clarify the responses of isolated human IAS to cholinergic and electrical field stimulation. ${ }^{26}$ The experiments reported represented data from 408 strips from 55 operative specimens.

Most strips relaxed to similar concentrations of acetylcholine via muscarinic receptors on non-adrenergic non-cholinergic (NANC) inhibitory enteric neurones. ${ }^{27}$ As the predominant inhibitory transmitter of NANC transmission in the IAS has now been identified as nitric oxide, it seems that acetylcholine relaxes the IAS by stimulating nitric oxide synthesis. They also demonstrated that bethanecol, a cholinergic agonist that selectively stimulates muscarinic receptors, relaxed IAS strips; this is consistent with in vivo observations by Guiterrez and Shah where an infusion of bethanecol lowered basal anal pressure by stimulation of inhibitory muscarinic receptors. ${ }^{11}$ Electrical field stimulation always caused relaxations by stimulation of these same NANC enteric inhibitory nerves. These relaxations were unaffected by hyoscine, propanolol, or hexamethonium which prevented relaxations to acetylcholine, isoprenaline, and DMPP, respectively. However, the response was prevented by tetrodotoxin, which blocks nerve action potential propagation, demonstrating the neural action of electrical field stimulation.

\section{The enteric nervous system}

The enteric nervous system was defined by Langley as a third division of the autonomic nervous system which receives inputs from the sympathetic and parasympathetic divisions. It exists as a separate entity between the gastrointestinal tract and comprises the internal and external submucous plexuses (Meissner's and Schbadach's plexus, respectively), the myenteric plexus (Auerbach's plexus), and the subserosal plexus, all of which are ganglionated. ${ }^{28}$ There are also non-ganglionated plexuses such as the deep muscular plexus and networks in the submucosa and lamina propria of the mucosa. Langley demonstrated histological differences between enteric neurones and neu- rones of other autonomic ganglia. ${ }^{4} \mathrm{He}$ also showed that the connections between fibres from the central nervous system and the enteric neurones differ from those between the central nervous system and other peripheral ganglia. Specifically, he noted the great discrepancy in number between the few fibres in nerves running to the intestine and the large populations of enteric nerve cells. In addition he pointed out the existence of complex local reflex pathways within the enteric nervous system which function as afferent, efferent, or interneuronal pathways. These constitute all the nervous components necessary for coordinated activities within the intramural plexuses, as exemplified by the rectoanal inhibitory reflex.

Numerous enteric neurotransmitters have now been identified, several of which may be released from the same neurone. The release of these transmitters may be affected by pre- and postsynaptic neural modulation.

\section{THE RECTOANAL INHIBITORY REFLEX}

In 1877 Gowers demonstrated that air injected into the rectum caused a rapid fall in anal canal pressure due to relaxation of the IAS, followed by a steady return to the initial resting pressure. ${ }^{29}$ This response is now known as the "rectoanal inhibitory reflex" (RAIR). A normal reflex is elicited in patients with cauda equina lesions ${ }^{30}$ and in individuals with spinal cord transection ${ }^{31}$ which clearly indicates that it is entirely intrinsic and independent of higher neural centres. The reflex is absent in Hirschsprung's disease, which is characterised by absence of ganglia in a variable length of the rectum and colon. It may be abolished temporarily after restorative rectal resection ${ }^{32}$ but in the long term is restored by regeneration of intramural neurones across the anastomosis. ${ }^{33}$ Sphincter function is often dependent on adjacent gastrointestinal movement and its tone altered through release of neurotransmitters. These are specific for each different gut sphincter. ${ }^{34}$

\section{ENTERIC INHIBITORY NEUROTRANSMITTERS}

The existence of enteric inhibitory neurones which are neither non-adrenergic nor non-cholinergic was first suggested by the work of Langley and Anderson in $1895 .^{35}$ Characterisation of the neurotransmitters involved came nearly 70 years later. Burnstock and colleagues recorded hyperpolarisations in intestinal muscle during stimulation of the intrinsic nerves in the presence of atropine and the adrenergic neurone blocker bretylium. Block of these hyperpolarisations by tetrodotoxin led Burnstock and his colleagues to conclude that they were inhibitory junction potentials in response to stimulation of NANC nerves. ${ }^{36-38}$ Inhibitory junction potentials are electrical events that underlie the relaxation of muscle; they are the hyperpolarising response of smooth muscle in response to nerve stimulation and as such they cause an inhibition of neurotransmission by inhibiting action potential propagation.

Circular muscle strips from the IAS often relax via NANC inhibitory nerves when exposed to electrical field stimulation. ${ }^{39}$ Burleigh and colleagues observed only relaxations in all 106 strips obtained from both the distal and proximal sphincter ${ }^{26}$ but Speakman and colleagues found that four of five control preparations showed a small contraction followed by relaxation. ${ }^{40}$ The contraction was abolished by the $\alpha$ adrenoceptor blocker phentolamine.

There has been an extensive search for the intramural NANC transmitter responsible for inducing IAS relaxation seen with rectal distension. The transmitters noradrenaline, acetylcholine, prostaglandins $\mathrm{E}_{2}$ and $\mathrm{F}_{2 \mathrm{a}}$, 5-hydoxytryptamine (5-HT), and dopamine have already been discounted as mediators for the RAIR ${ }^{26}$ Over the past two decades work has concentrated on the function of adenosine triphosphate (ATP), vasoactive intestinal pep- 
tide (VIP), and nitric oxide (NO) and their role in mediating the RAIR, as they are known to act together in mediating enteric inhibitory cotransmission in other areas of the gut.

\section{Adenosine triphosphate (ATP)}

There is evidence to suggest that ATP is a neurotransmitter in the enteric nervous system, and release of ATP through electrical stimulation of enteric nerves has been measured. The pharmacological responses to ATP can be blocked by purinoceptor antagonists such as suramin or reactive blue $2 .{ }^{6}$ Although reliable histochemical stains for ATP are not known, a fluorescence technique involving quinacrine, which forms complexes with ATP, has been developed. Quinacrine is known to bind to compounds with transmitter-like properties, although its efficacy for neurones that have a high ATP content is uncertain. Despite its inhibitory action in other parts of the gut, there is no evidence of such a role for ATP in the IAS. ${ }^{26}$

\section{Vasoactive intestinal peptide (VIP)}

VIP has been identified as an inhibitory transmitter mediating lower oesophageal relaxation. ${ }^{41}{ }^{42}$ VIP neurones have been localised in the IAS, ${ }^{43}$ and VIP is released in the venous effluent from the rectum following neural stimulation. ${ }^{44}$ Biancani and colleagues demonstrated that preincubation with VIP antisera inhibited relaxation of IAS strips in response to both exogenously applied VIP and electrical field stimulation. ${ }^{45}$ Nurko and colleagues used specific VIP antagonists to demonstrate VIP as a NANC transmitter. ${ }^{46}$ The role of other cotransmitters cannot be discounted as VIP antagonists fail to inhibit completely IAS relaxation in response to lower levels $(0.5 \mathrm{~Hz})$ of neural field stimulation.

Nitric oxide (NO)

From their work on isolated strips of opossum IAS, Rattan and Chakder suggested the possibility of $\mathrm{NO}$ as an inhibitory neurotransmitter of NANC nerves in the human IAS. ${ }^{47}$ Firstly, they showed that NO caused tetrodotoxin resistant relaxation in these strips. Secondly, they showed that $\mathrm{L}-\mathrm{N}^{\mathrm{G}}$-nitro-arginine, the NO synthesis inhibitor, caused stereoselective suppression of the fall in IAS tension due to electrical field stimulation; this effect was counteracted after application of the endogenous precursor of NO, L-arginine. This latter finding is consistent with Burleigh's observations that $\mathrm{L}-\mathrm{N}^{\mathrm{G}}$-nitro-arginine reduced NANC relaxations of the human gut. ${ }^{48}$ Rattan and Chakder also suggested that NO worked in conjunction with VIP as $\mathrm{L}-N^{\mathrm{G}}$-nitro-arginine also suppressed the fall in resting tension of IAS in response to VIP. ${ }^{47}$

In further work on opossums, Chakder and Rattan demonstrated by chemiluminescence that $\mathrm{NO}$ was released in response to NANC stimulation. ${ }^{49}$ O'Kelly and colleagues, in similar experiments on isolated human IAS strips, demonstrated a concentration dependent inhibition of IAS relaxation to electrical field stimulation by application of $\mathrm{L}-N^{\mathrm{G}}$-nitro-arginine or the weaker competitive analogue of L-arginine, $N$-monomethyl-L-arginine. ${ }^{50}$ However, the inhibitory effect of $\mathrm{L}-N^{\mathrm{G}}$-nitro-arginine was complete, disputing the involvement of other transmitters.

Using nitric oxide synthase immunoreactivity and nicotinamide adenine dinucleotide phosphate (NADPH) diaphorase histochemistry, O'Kelly and colleagues presented morphological data suggesting that in the human anorectum NO synthase containing neurones and their processes have the appropriate characteristics to serve as inhibitory motor nerves between the rectum and anal canal. ${ }^{51}$ Bult and colleagues demonstrated release of NO from NANC nerves. ${ }^{52}$ In a guinea pig model, Stebbing, using retrograde neuronal tracing and enzyme histochemistry, described direct anatomical evidence of an efferent descending nitrergic rectoanal pathway appropriate to mediating the motor response of the RAIR. ${ }^{53} \mathrm{NO}$ activates soluble guanylate cyclase thereby increasing production of cyclic guanosine-3'5'-monophosphate (cGMP) and relaxation of smooth muscle. NO is important in the RAIR but other transmitters may have a role.

\section{Smooth muscle contraction and maintenance of tone}

Autonomic and enteric neural stimulation regulates smooth muscle contraction in the IAS. Contraction of the IAS translates clinically into an increase in anal tone.

Muscle contraction is regulated by changes in cytosolic calcium $\left(\mathrm{Ca}^{2+}\right)$ levels. Smooth muscle differs from striated muscle in the way that its contractile elements are activated. The two major contractile proteins in both muscle types are actin and myosin, which are structural components of the thin and thick filaments, respectively.

In smooth muscle, $\mathrm{Ca}^{2+}$ regulation is affected via the various regulatory proteins, including the myosin light chains, calmodulin, caldesmon, and calponin. $\mathrm{Ca}^{2+}$ release into the myoplasm occurs either by entry through voltage gated or receptor operated channels or by release from the sarcoplasmic reticulum via inositol triphosphate (fig 1). $\mathrm{Ca}^{2+}$ binds to calmodulin which then activates myosin light chain kinase thus inducing phosphorylation of the regulatory light chains of myosin. If actin has been activated by caldesmon, phosphorylated myosin then attaches to actin; this results in the production of tension. Dephosphorylation of myosin induces either relaxation or may allow cross bridges to enter the "latch state" which is defined as a state of prolonged contraction in the smooth muscle with a low frequency of cross bridge cycling. The precise mechanisms responsible for this maintenance of smooth muscle tone are still not entirely known.

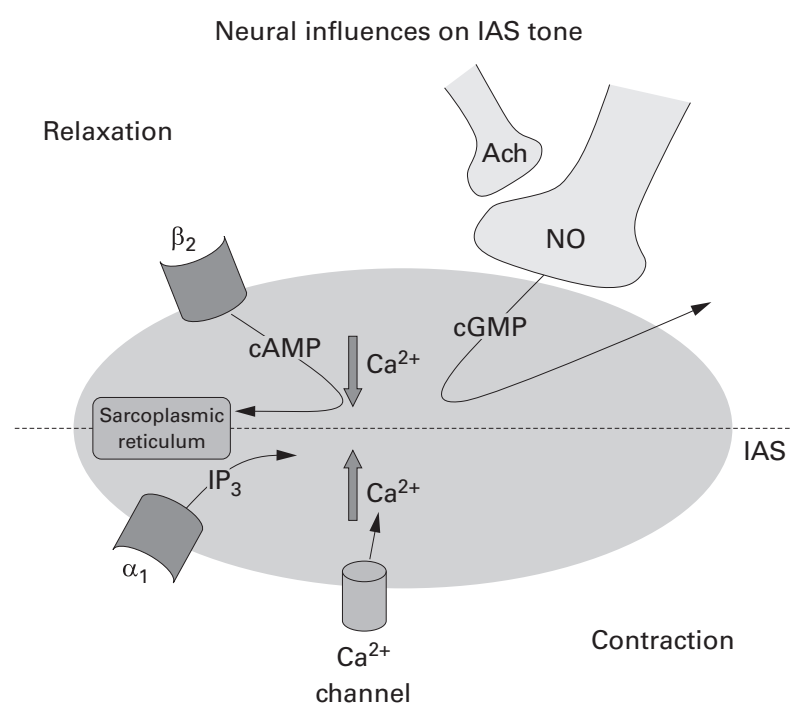

Figure 1 Internal anal sphincter (IAS) smooth muscle cell contraction is dependent on an increase in cellular calcium $\left(\mathrm{Ca}^{2+}\right)$. This can be produced by direct influx of calcium through membrane $\mathrm{Ca}^{2+}$ channels or by stimulation of $\alpha_{1}$ adrenoceptors. The latter pathway results in release of $\mathrm{Ca}^{2+}$ from the sarcoplasmic reticulum mediated via inositol-1'4'5'triphosphate $\left(\mathrm{IP}_{3}\right)$. Relaxation is induced by antagonising membrane $\mathrm{Ca}^{2+}$ channels or $\alpha_{1}$ adrenoceptors. Stimulation of $\beta_{2}$ adrenoceptors results in a return of $\mathrm{Ca}^{2+}$ to the sarcoplasmic reticulum, mediated through cyclic adenine-3'5'-monophosphate (cAMP). Stimulation of nitric oxide (NO) containing non-adrenergic non-cholinergic (NANC) enteric neurones induces a cyclic guanosine-3'5'-monophosphate (cGMP) mediated decrease in cellular $\mathrm{Ca}^{2+}$. Muscarinic nerve stimulation, through release of acetylcholine (Ach), promotes the synthesis of NO. 
Relaxation of smooth muscle occurs when there is a resulting decrease in cytosolic $\mathrm{Ca}^{2+}$. This is effected through cellular mechanisms similar to those for contraction (fig 1). In vitro studies of porcine IAS have shown that tone and spontaneous activity depend on extracellular $\mathrm{Ca}^{2+}$ and flux across the cell membrane whereas agonist induced contractions depend mainly on $\mathrm{Ca}^{2+}$ release from the intracellular sarcoplasmic reticulum. ${ }^{54}$ Understanding the mechanisms that maintain tone and muscle contraction in relation to cellular $\mathrm{Ca}^{2+}$ aid the treatment of smooth muscle contractile abnormalities.

\section{Pathophysiology of anal fissures and rationale of therapy}

Most anal fissures are idiopathic with no identified underlying disease process. ${ }^{556}$ The remaining fissures are associated with trauma (obstetric or surgical), Crohn's disease, syphilis, human immunodeficiency virus (HIV), or tuberculosis.

Recognised features common to most chronic anal fissures are a high resting anal canal pressure due to hypertonicity of the internal anal sphincter, ${ }^{57-60}$ reduced vascular perfusion index at the site of the anal fissure, ${ }^{6162}$ and the presence of "ultraslow" pressure wave activity in the IAS. ${ }^{59}{ }^{63}$ It is generally believed that small traumatic tears in the lining of the anal canal fail to heal due to a reduced blood supply, and produce chronic anal fissures.

Simple therapeutic measures such as bulk laxatives, topical local anaesthetics, silver nitrate cautery, sitz baths, and anal dilators have been disappointing. In a study of 393 patients treated with cautery, suppositories and sitz baths, $44.4 \%$ of patients healed in the short term but $27.2 \%$ of these developed recurrent anal fissures over a five year follow up period. ${ }^{64}$

Current treatment is aimed at reducing resting anal pressure by diminishing sphincter tone and improving blood supply at the site of the fissure, thus promoting the healing rate. Manual dilatation of the anus is a simple procedure and has therefore been a popular treatment option. Recently, with the introduction of endoanal ultrasound, insight has been gained on the degree of uncontrolled tearing of the anal sphincter muscles during this procedure. ${ }^{65} 66$ Although it still has its advocates ${ }^{67}$ lateral sphincterotomy has become the vogue and appears to be generally more effective and safer, although there is a risk of disrupting continence. In long term studies, approximately $35 \%$ of patients were found to be incontinent of flatus, $5 \%$ had faecal soiling, ${ }^{68}$ and endoanal ultrasound also demonstrated extensive internal anal sphincteric defects in some patients. ${ }^{69}$

The anal advancement flap is an alternative treatment for women with a complicated obstetric history and in patients with recurrent or persistent fissures following lateral sphincterotomy. This operation avoids further disruption to the internal sphincter. ${ }^{70}$

\section{Chemical sphincterotomy}

A pharmacological approach to the treatment of anal fissures is an alternative modality to lateral sphincterotomy. It appears equally effective in reducing anal sphincter tone and is free from long term complications. ${ }^{51}$ This is achievable by enhancing IAS relaxation via nitric oxide donation, intracellular $\mathrm{Ca}^{2+}$ depletion, muscarinic receptor stimulation, $\alpha$ adrenergic inhibition, or $\beta$ adrenergic stimulation.

NITRIC OXIDE DONORS

$\mathrm{NO}$ is recognised as the predominant neurotransmitter mediating neurogenic relaxation of the human IAS. ${ }^{50}$ Sodium nitroprusside, an exogenous source of NO, mimics the effect of electrical field stimulation in relaxing the human IAS in vitro. ${ }^{50}$ Glyceryl trinitrate (GTN) also acts as an NO donor and is available as an ointment for topical administration. Topical isosorbide dinitrate has a similar action. NO donors probably aid healing through an increase in local blood flow secondary to a reduction in intra-anal pressure and perhaps also by vasodilatation of the vessels supplying the anal musculature.

Kennedy et al reported GTN use for treating anal fissures. ${ }^{72}$ Loder et al showed that application of a $2 \%$ preparation of GTN ointment (Percutol; Cusi Labs, Haslemere, UK) or $0.5 \%$ or $1 \%$ diluted in paraffin caused headaches lasting several hours. ${ }^{73}$ A $0.2 \%$ GTN ointment was better tolerated and reduced anal maximal resting pressure by $27 \%$ in volunteers. Lund et al observed headaches after application of $0.4 \%$ but not $0.2 \%$ GTN ointment to the anoderm of healthy volunteers. ${ }^{74}$ In subsequent studies they reported a healing rate of $68-86 \%$, and a $33 \%$ reduction in maximum resting anal pressure using $0.5 \mathrm{~g}$ of $0.2 \%$ GTN ointment twice daily for at least six weeks. ${ }^{74}{ }^{75}$ Mild headaches occurred in $20 \%$ of patients. ${ }^{74}$ Gorfine obtained similar results in 15 patients with $0.5-1 \mathrm{~g}$ of $0.5 \%$ GTN ointment used four times daily. ${ }^{76}$ At four weeks all of the acute, but none of the chronic, fissures had healed. In later studies with $200 \mathrm{mg}$ of $0.3 \%$ GTN ointment applied four times daily, the fissure had healed in $77 \%$ of patients at eight weeks and $22 \%$ experienced headaches. ${ }^{77}$ Watson and colleagues found that a minimum concentration of $0.2 \%$ GTN ointment was required in 15 of 19 patients with chronic anal fissures to reduce the maximum resting pressure by $25 \%{ }^{78}$ At six weeks only nine $(47 \%)$ patients had healed most of whom required a concentration of not less than $0.3 \%$.

While the therapeutic role of GTN in the treatment of anal fissures is convincing, unresolved issues regarding its use are the optimal therapeutic dose with the minimal side effects and the long term benefit. Carapeti et al, in a double blind controlled trial, randomised 70 patients to receive placebo, $0.2 \% \mathrm{GTN}$, or increasing concentrations of GTN. ${ }^{79}$ They concluded that GTN heals two thirds of chronic anal fissures but with a high incidence of side effects $(72 \%)$; there was no advantage in using higher doses than $0.2 \%$ GTN. The phenomenon of tachyphylaxis was not noted as successive increments in the dose of GTN also healed anal fissures. ${ }^{79}$ The medium term follow up (median 28 months) after successful initial treatment with GTN has recently been published for 41 patients. Of these, 30 (73\%) remained symptom free, and of the 11 patients with recurrent symptoms, six responded to a further course of GTN, two healed spontaneously, and three required sphincterotomy. ${ }^{80}$

Alternative nitrates such as isosorbide dinitrate (ISDN) have been investigated. ISDN used in 34 patients $(1 \mathrm{~g}$ of $1 \%$ ointment applied every three hours throughout the day) achieved a healing rate of $88 \%{ }^{81}$ Similar results were obtained by Lysy et al who demonstrated healing in $83 \%$ of 41 patients following use of topical ISDN in a dose of $1.25 \mathrm{mg}$ or $2.5 \mathrm{mg}$ applied three times a day. ${ }^{82}$

CALCIUM ANTAGONISTS

Nifedipine (a $\mathrm{Ca}^{2+}$ channel antagonist), which has been used in the management of achalasia, ${ }^{83}$ decreases anal sphincter tone if given sublingually ${ }^{84}$ or orally. ${ }^{85}$ The first clinical study of the role of calcium antagonists on anal canal pressure was conducted by Chrysos and colleagues ${ }^{84}$; 30 minutes after $20 \mathrm{mg}$ of sublingual nifedipine was administered to 10 patients (with non-prolapsing haemorrhoids or anal fissures) and 10 volunteers there was a $32 \%$ and $24 \%$ reduction in anal canal pressure, respectively. There was no significant effect on blood pressure or heart 
rate, but three subjects had either a transient headache or facial flushing lasting up to 30 minutes. An oral dose of $20 \mathrm{mg}$ twice daily was used to treat 15 patients with chronic anal fissures. ${ }^{85}$ The initial dose of nifedipine caused a $36 \%$ fall in anal mean resting pressure and healing was achieved in $60 \%$ by eight weeks. The principal side effect was flushing of the face and limbs which was usually short lived. Carapeti et al demonstrated the effectiveness of another $\mathrm{Ca}^{2+}$ channel antagonist, diltiazem, in decreasing anal canal pressure. ${ }^{86}{ }^{87}$ In a non-randomised pilot study, 10 of 15 patients healed using a $2 \%$ gel without any reported side effects. ${ }^{88}$

\section{MUSCARINIC AGONISTS}

Few studies have involved topical muscarinic agonists. These agents promote the synthesis of nitric oxide in NANC neurones. Bethanecol, used as a topical cream in a pilot study, decreased anal sphincter pressure and healed fissures without side effects. ${ }^{88}$ Rates of healing may be similar to those with GTN and diltiazem.

\section{SYMPATHETIC NEUROMODULATORS}

$\alpha_{1}$ Adrenoceptor antagonists have been used in the management of symptomatic urethral obstruction caused by $\alpha$ adrenoceptor mediated contraction of stromal smooth muscle within benign prostatic hypertrophy. ${ }^{89}$ Inhaled salbutamol shortens attacks of severe pain in patients with proctalgia fugax. ${ }^{90}$ Oral indoramin (an $\alpha_{1}$ antagonist) and salbutamol (a $\beta_{2}$ agonist) have both been shown to reduce anal canal pressure by relaxing the IAS in healthy volunteers and patients with anal fissures. ${ }^{91}{ }^{92}$ While there is no apparent difference in the $\alpha$ adrenoceptors in the IAS of patients with anal fissures compared with controls, as measured by the comparative reduction in anal canal pressure after administration of indoramin, $\beta$ adrenoceptors are probably up regulated in patients with anal fissures as the reduction in anal canal pressure is higher in fissure patients than in controls. ${ }^{92}$ The up regulated $\beta$ adrenoceptors have also been demonstrated by in vitro studies. Supersensitivity to relaxation by isoproterenol was demonstrated in IAS strips removed from patients undergoing lateral sphincterotomy compared with IAS strips removed from patients with third degree haemorrhoids and normal anal canal pressures. $^{93}$ The effectiveness of these drugs in the treatment of anal fissures has yet to be evaluated.

\section{BOTULINUM TOXIN}

Clostridium botulinum produces several toxins, of which types A, B, and $\mathrm{E}$ have been linked to cases of botulism in humans. Botulinum toxin type $\mathrm{A}$ is of therapeutic value in various neurological and opthalmological disorders. Brooks in the 1950s suggested that botulinum neurotoxin type A (BoNT/A) might be used to reduce muscle hyperactivity. ${ }^{94}$ BoNT/A was first used clinically by Scott (1977) as an injection into the extraocular muscles to treat strabismus. ${ }^{95}$

In the gastrointestinal tract botulinum toxin was first used to treat achalasia. ${ }^{96}$ BoNT/A acts presynaptically by blocking acetylcholine release at the neuromuscular junction. Although this mode of action on the striated external anal sphincter is clear, its precise mechanism on the IAS is less so since muscarinic terminals act on NANC neurones. Nevertheless injection of this toxin into either the external or internal anal sphincter reduces anal canal pressure, and this has been used to treat anal fissures.

Jost et al injected 2.5 U of Botox (Allergan Pharmaceuticals, Irvine, California, USA) into the EAS on both sides of a chronic anal fissure. ${ }^{97-100}$ In a series of 100 patients $78 \%$ were pain free at one week, $82 \%$ healed at three months, and $79 \%$ were healed at six months. ${ }^{101}$ There was a $10 \%$ incidence of perianal thrombosis. Espi et al injected 20 patients with 5 units of Botox on either side of an anal fissure, and 16 patients with an additional 5 units below the fissure. The healing rate was $65 \%$ and $81 \%$, respectively, at six months. ${ }^{102}$

Gui et al, using three injections of 5 units into the IAS laterally and posteriorly, had a $60 \%$ healing rate at two months, although one patient developed transient incontinence of flatus. ${ }^{103}$ In a larger randomised series comparing botulinum toxin with saline injections in 30 patients, healing rates at two months improved to $73 \%$ in the treatment group compared with $13 \%$ in the control group. ${ }^{104}$

Recent work by Jost and Schrank with an alternative form of botulinum toxin, Dysport (Ipsen Pharmaceuticals) showed that in a series of 50 patients, using doses of 10 units and 20 units injected adjacent to the fissure margins, $78 \%$ of patients had healed by three months. ${ }^{105}$ There was no significant difference in healing rates between the two groups but those patients on the higher dosage showed a greater reduction in sphincter tone of the puborectalis muscle and a higher incidence of transient incontinence.

Despite the reported success of botulinum toxin its use has not been widely adopted, possibly due to the need for injection into the sphincter complex and because it is expensive. The optimal dose and method of administration require validation.

\section{OTHER POTENTIAL AGENTS}

The expansion of novel therapies to modulate anal sphincter tone is based on the understanding of the innervation of the IAS. Trimebutine (3,4,5-trimethoxybenzoic acid 2-(dimethylamino)-2-phenylbutylester) causes the release and modulation of peptides and has actions mediated through opiate receptors. ${ }^{106}$ Trimebutine $200 \mathrm{mg}$ three times daily was more effective than a daily dose of $400 \mathrm{mg}$ of mebeverine in reducing the frequency, duration, and intensity of pain attacks in patients with irritable bowel syndrome. ${ }^{107}$ Ho et al investigated the role of trimebutine to determine whether it reduced anal sphincter spasm and thus relieved pain after haemorrhoidectomy. ${ }^{108}$ In their randomised trial 80 patients received trimebutine as a suppository; this resulted in a mean reduction in resting anal canal pressure of $35 \%$ but no difference in pain scores at four hours after the procedure. The pharmacological action of trimebutine on the IAS and its potential role in the treatment of anal fissures have yet to be defined.

\section{Conclusion}

Since Langley's first description of the autonomic nervous system over 100 years ago, much progress has been made in defining the neural pathways and their associated neurotransmitters. The recent discovery of the role of nitric oxide in IAS relaxation and the encouraging success with the use of glyceryl trinitrate have prompted interest in other agents, ${ }^{109}$ and opened the field for the pharmacological modulation of the IAS in treating anal fissures. R BHARDWAJ
C J VAIZEY
P B BOULOS

Department of Surgery, University College London,

Charles Bell House, 67-73 Riding House Street,

London W1P $7 L D, U K$

C H V HOYLE

Department of Anatomy

Correspondence to: Professor P B Boulos.

Email: e.collins@ucl.ac.uk

1 Frenckner B, Ihre T. Influence of autonomic nerves on the internal anal sphincter in man. Gut 1976;17:306-12.

2 Frenckner B. Function of the anal sphincters in spinal man. Gut 1975; 16:638-44. 
3 Kuntz A. The autonomic nervous system, 3rd edn. London: Balliere, Tindall and Cox, 1946

4 Langley JN. The autonomic nervous system. Part 1. Cambridge: Heffer and sons Ltd $1921: 1-14$

5 Dale HH. Nomenclature of fibres in the autonomic nervous system and their effects. F Physiol 1933;80:10-11.

6 Hoyle CHV. Purinergic cotransmission: parasympathetic and enteric nerves. Neurosciences 1996;8:207-15.?

7 Hoyle CHV. Neuropeptides: Essential data. Chichester: John Wiley and sons, 1996.

8 De Ponti F, Giaroni C, Cosentino M, Lecchini S, Frigo G. Adrenergic mechanisms in the control of gastrointestinal motility: from basic science to clinical applications. Pharmacol Ther 1996;69:59-78

9 Schuster MM. Motor action of rectum and anal sphincters in continence and defaecation. Handbook of physiology, alimentary canal, vol 4 No 6. Washington DC: Physiological Society, 1968:2121-39.

10 Frenckner B, Euler CV. Influence of pudendal block on the function of the anal sphincters. Gut 1975;16:482-9.

11 Guiterrez JG, Shah AN. Autonomic control of the internal anal sphincter in man. International Symposium of Gastrointestinal Motility. Herentals, Belgium: Typoff Press, 1975:363-73.

12 Gaskell WH. The Involuntary Nervous System. 1920. London: Longman Inc., 1920

13 Learmonth JR. Studies on the function of the lumbar sympathetic outflow. Am f Physiol 1929;89:686-91.

14 Rankin FW, Learmonth JR. Section of the sympathetic nerves of the distal part of the colon and rectum in the treatment of Hirschsprung's disease and certain types of constipation. Ann Surg 1930;92:710-20.

15 Shepherd JJ, Wright PG. The response of the internal anal sphincter in man to stimulation of the presacral nerve. Am F Dig Dis 1968;13:421-7.

16 Carlstedt A, Fasth S, Hulten L, Nordgren S. The sympathetic innervation of the internal anal sphincter and rectum in the cat. Acta Physiol Scand 1988; 133:423-31.

17 Mizutani M, Nakayama S. Role of lumbar colonic nerves on internal anal sphincter motility in dogs. Ital f Gastroenterol 1986;18:134-9.

18 Shibamoto T, Chakder S, Rattan S. Role of hypogastric nerve activity in opossum internal anal sphincter function: influence of surgical and chemical denervation. F Pharmacol Exp Ther 1994;271:277-84.

19 Lubowski DZ, Nicholls RJ, Swash M, Jordan MJ. Neural control of internal anal sphincter function. Br F Surg 1987;74:668-70.

20 Kerremans R, Penninckx F. A study in vivo of adrenergic receptors in the rectum and in the internal anal sphincter of the cat. Gut 1970;11:709-14

21 Penninckx F, Kerremans R, Beckers J. Pharmacological characteristics of the non-striated anorectal musculature in cats. Gut 1973;14:393-8.

22 Yamato S, Rattan S. Role of alpha adrenoceptors in opossum internal anal sphincter. F Clin Invest 1990;86:424-9.

23 Parks AG, Fishlock DJ, Cameron JD, May H. Preliminary investigation of the pharmacology of the human internal anal sphincter. Gut 1969;10:674-

24 Friedmann CA. The action of nicotine and catecholamines on the human internal anal sphincter. Am f Dig Dis 1968;13:428-31.

25 Bass DD, Ustach TJ, Schuster MM. In vitro pharmacologic differentiation of sphincteric and non- sphincteric muscle. fohns Hopkins Med 7 1970;127: 185-91.

26 Burleigh DE, D’Mello A, Parks AG. Responses of isolated human internal anal sphincter to drugs and electrical field stimulation. Gastroenterology 1979;77:484-90.

27 Buckley NJ, Caulfield M. Transmission: acetylcholine. In: Burnstock G, Hoyle CHV, eds. Autonomic neuroeffector mechanisms. Switzerland: Harwood Academic Publishers, 1992:293-6.

28 Furness JB, Costa M. The enteric nervous system. New York: Churchill Livingstone, 1987:1-5.

29 Gowers WR. The autonomic action of the sphincter ani. Proc $R$ Soc Lond 1877;26:77-84

30 Denny-Brown D, Robertson EG. An investigation of the nervous control of defaecation. Brain 1935;58:256-310.

31 Burleigh DE, D'Mello A. Neural and pharmacologic factors affecting motility of the internal anal sphincter. Gastroenterology 1983;84:409-17.

32 Schuster MM, Hendrix TR, Mendelhof AI. The internal anal sphincter response: manometric studies on its normal physiology, neural pathways, and alteration in bowel disorders. F Clin Invest 1963;42:196-207.

33 Lane RH, Parks AG. Function of the anal sphincters following colo-anal anastomosis. Br f Surg 1977;64:596-9.

34 Bennett A, Whitney B. A pharmacological study of the motility of the human gastrointestinal tract. Gut 1966;7:307-16.

35 Langley JN, Anderson HK. The innervation of pelvic and adjoining viscera. F Physiol 1895;19:122-30.

36 Bennett MR, Burnstock G, Holman M. Transmission from intramural inhibitory nerves to the smooth muscle of the guinea-pig taenia coli. F Physiol (Lond) 1966;182:541-58.

37 Burnstock G, Campbell G, Bennett M, Holman ME. Inhibition of the smooth muscle of the taenia coli. Nature 1963;200:581-2.

38 Burnstock G, Campbell G, Bennett M, Holman ME. Innervation of the guinea-pig taenia coli: are there intrinsic inhibitory nerves which are guinea-pig taenia coli: are there intrinsic inhibitory nerves which
distinct from sympathetic nerves? Int $\mathcal{f}$ Neuropharm 1964;3:163-6.

39 Burleigh DE. Non-cholinergic, non-adrenergic inhibitory neurons in human internal anal sphincter muscle. 7 Pharm Pharmacol 1983;35:258-60.

40 Speakman CT, Hoyle CH, Kamm MA, et al. Adrenergic control of the internal anal sphincter is abnormal in patients with idiopathic faecal incontinence. Br F Surg 1990;77:1342-4.

41 Biancani P, Walsh JH, Behar J. Vasoactive intestinal polypeptide. A neurotransmitter for lower esophageal sphincter relaxation. $\mathcal{F}$ Clin Invest 1984;73:963-7.

42 Goyal RKS, Rattan S, Said S. VIP as a possible neurotransmitter of non-cholinergic, non-adrenergic inhibitory neurones. Nature 1980;288: $378-80$

43 Alumets J, Hakanson R, Sundler F, Uddman R. VIP innervation of sphincters. Scand $\mathcal{7}$ Gastroenterol 1978; 13 (suppl 49): 6

44 Andersson PO, Bloom SR, Edwards AV, Jarhult J, Mellander S. Neural vasodilator control in the rectum of the cat and its possible mediation by vasoactive intestinal polypeptide. F Physiol (Lond) 1983;344:49-67.

45 Biancani P, Walsh J, Behar J. Vasoactive intestinal peptide: a neurotransmitter for relaxation of the rabbit internal anal sphincter. Gastroenterology 1985;89:867-74.
46 Nurko S, Dunn BM, Rattan S. Peptide histidine isoleucine and vasoactive intestinal polypeptide cause relaxation of opossum internal anal sphincter via two distinct receptors. Gastroenterology 1989;96:403-13.

47 Rattan S, Chakder S. Role of nitric oxide as a mediator of internal anal sphincter relaxation. Am f Physiol 1992;262:G107-12.

48 Burleigh DE. Ng-nitro-L-arginine reduces nonadrenergic, noncholinergic relaxations of human gut. Gastroenterology 1992;102:679-83.

49 Chakder S, Rattan S. Release of nitric oxide by activation of nonadrenergic G7-12.

50 O'Kelly T, Brading A, Mortensen N. Nerve mediated relaxation of the human internal anal sphincter: the role of nitric oxide. Gut 1993;34:68993

51 O'Kelly TJ, Davies JR, Brading AF, Mortensen NJ. Distribution of nitric oxide synthase containing neurons in the rectal myenteric plexus and anal canal. Morphologic evidence that nitric oxide mediates the rectoanal inhibitory reflex. Dis Colon Rectum 1994;37:350-7.

52 Bult H, Boeckxstaens GE, Pelckmans PA, et al. Nitric oxide as an inhibitory non-adrenergic non-cholinergic neurotransmitter (see comments). Nature 1990;345:346-7.

53 Stebbing JF. Nitric oxide synthase neurones and neuromuscular behaviour of the anorectum. Ann R Coll Surg Engl 1998;80:137-45.

54 Cook TA, Brading AF, Mortensen NJ. Differences in contractile properties of anorectal smooth muscle and the effects of calcium channel blockade. $\mathrm{Br}$ 7 Surg 1999;86:70-5.

55 Lund JN, Scholefield JH. Aetiology and treatment of anal fissure (see comments). Br F Surg 1996;83:1335-44.

56 Schouten WR, Briel JW, Auwerda JJ, Boerma MO. Anal fissure: new concepts in pathogenesis and treatment. Scand F Gastroenterol Suppl 1996; 218:78-81.

57 Farouk R, Duthie GS, MacGregor AB, Bartolo DC. Sustained internal sphincter hypertonia in patients with chronic anal fissure. Dis Colon Rectum 1994;37:424-9.

58 Gibbons CP, Read NW. Anal hypertonia in fissures: cause or effect? $\mathrm{Br} \mathcal{F}$ Surg 1986;73:443-5.

59 Hancock BD. The internal sphincter and anal fissure. $\mathrm{Br} f$ Surg 1977;64:92-5.

60 Nothmann BJ, Schuster MM. Internal anal sphincter derangement with anal fissures. Gastroenterology 1974;67:216-20.

61 Schouten WR, Briel JW, Auwerda JJ, De Graaf EJ. Ischaemic nature of anal fissure. Br F Surg 1996;83:63-5

62 Schouten WR, Briel JW, Auwerda JJ. Relationship between anal pressure and anodermal blood flow. The vascular pathogenesis of anal fissures. Dis Colon Rectum 1994;37:664-9.

63 Schouten WR, Blankensteijn JD. Ultra slow wave pressure variations in the anal canal before and after lateral internal sphincterotomy. Int $\mathcal{f}$ Colorectal Dis 1992; 7:115-18.

64 Shub HA, Salvati EP, Rubin RJ. Conservative treatment of anal fissure: an unselected, retrospective and continuous study. Dis Colon Rectum 1978;21: $582-3$.

65 MacDonald A, Smith A, McNeill AD, Finlay IG. Manual dilatation of the anus. Br F Surg 1992;79:1381-2.

66 Speakman CT, Burnett SJ, Kamm MA, Bartram CI. Sphincter injury after anal dilatation demonstrated by anal endosonography. Br F Surg 1991;78: 1429-30.

67 Strugnell NA, Cooke SG, Lucarotti ME, Thomson WH. Controlled digital anal dilatation under total neuromuscular blockade for chronic anal fissure: a justifiable procedure. Br F Surg 1999;86:651-5.

68 Khubchandani IT, Reed JF. Sequelae of internal sphincterotomy for chronic fissure in ano. Br F Surg 1989;76:431-4.

69 Sultan AH, Kamm MA, Nicholls RJ, Bartram CI. Prospective study of the extent of internal anal sphincter division during lateral sphincterotomy. Dis Colon Rectum 1994;37:1031-3.

70 Nyam DC, Wilson RG, Stewart KJ, Farouk R, Bartolo DC. Island advancement flaps in the management of anal fissures. Br F Surg 1995;82:326-8.

71 Madoff RD. Pharmacologic therapy for anal fissure. $N$ Engl f Med 1998;338:257-9.

72 Kennedy ML, Lubowski DZ, King, DW. Chemical sphincterotomy for anal fissure. Tripartite Meeting, Sydney 1993 as quoted by Watson SJ, Kamm MA, Nicholls RJ, Phillips RKS. Topical glyceryl trinitrate in the treatment of chronic anal fissure. Br f Surg 1996;83:771-5.

73 Loder PB, Kamm MA, Nicholls RJ, Phillips RK. 'Reversible chemical sphincterotomy' by local application of glyceryl trinitrate. Br f Surg 1994; 81:1386-9.

74 Lund JN, Armitage NC, Scholefield JH. Use of glyceryl trinitrate ointment in the treatment of anal fissure. Br F Surg 1996;83:776-7.

75 Lund JN, Scholefield JH. A randomised, prospective, double-blind, placebo-controlled trial of glyceryl trinitrate ointment in treatment of anal fissure (see comments) (published erratum appears in Lancet 1997;349: 656). Lancet 1997;349:11-14

76 Gorfine SR. Treatment of benign anal disease with topical nitroglycerin. Dis Colon Rectum 1995;38:453-6.

77 Gorfine SR. Topical nitroglycerin therapy for anal fissures and ulcers (letter). N Engl f Med 1995;333:1156-7.

78 Watson SJ, Kamm MA, Nicholls RJ, Phillips RK. Topical glyceryl trinitrate in the treatment of chronic anal fissure. Br F Surg 1996;83:771-5.

79 Carapeti EA, Kamm MA, McDonald PJ, et al. Randomised controlled trial shows that glyceryl trinitrate heals anal fissures, higher doses are not more effective, and there is a high recurrence rate. Gut 1999;44:727-30.

80 Lund JN, Scholefield JH. Follow-up of patients with chronic anal fissure treated with topical glyceryl trinitrate (letter). Lancet 1998;352:1681.

81 Schouten WR, Briel JW, Boerman MO, et al. Pathophysiological aspects and clinical outcome of intra-anal application of isosorbide dinitrate in patients with chronic anal fissure. Gut 1996;39:465-9

82 Lysy J, Israelit-Yatzkan Y, Sestiere-Ittah M, Keret D, Goldin E. Treatment of chronic anal fissure with isosorbide dinitrate: long-term results and dose determination. Dis Colon Rectum 1998;41:1406-10.

83 Traube M, Dubovik S, Lange RC, McCallum RW. The role of nifedipine therapy in achalasia: results of a randomized, double-blind, placebocontrolled study. Am f Gastroenterol 1989;84:1259-62.

84 Chrysos E, Xynos E, Tzovaras G, et al. Effect of nifedipine on rectoanal motility. Dis Colon Rectum 1996;39:212-6. 
85 Cook TA, Smiglin Humpheys MM, Mortensen NJ. Oral nifedipine is an effective treatment for chronic anal fissures. Colorectal Dis 1999;1 (suppl 1): 134 .

86 Carapeti EA, Kamm MA, Evans BE, Phillips RKS. Topical and oral diltiazem lower anal sphincter pressure. Br F Surg 1998;85 (suppl 1):80-1.

87 Carapeti EA, Kamm MA, Evans BE, Phillips RKS. Diltiazem lowers resting anal sphincter pressure-A potential low side-effect alternative to glyceryl trinitrate for fissures. Gastroenterology 1998;114:A7.

88 Carapeti EA, Kamm MA, Evans BE, Phillips RKS. Diltiazem and bethanecol decrease anal sphincter pressure and heal anal fissures without side effects. Gut 1999;45:719-22.

89 Hieble JP, Ruffolo RR Jr. The use of alpha-adrenoceptor antagonists in the pharmacological management of benign prostatic hypertrophy: an overview. Pharmacol Res 1996;33:145-60.

90 Eckardt VF, Dodt O, Kanzler G, Bernhard G. Treatment of proctalgia fugax with salbutamol inhalation. Am f Gastroenterol 1996;91:686-9.

91 Pitt J, Henry MM, Craggs MD, Boulos PB. A potential new medical therapy for chronic anal fissure. Int $\mathcal{F}$ Colorectal Dis 1997;12:169.

. ojo-Arom son of alphat and beta adrenoceptor function of the internal anal sphincter

93 Regadas FS, Batista LK, Albuquerque JL, Capaz FR. Pharmacological Regadas FS, Batista LK, Albuquerque JL, Capaz FR. Pharmacological
study of the internal anal sphincter in patients with chronic anal fissure. $B r$ I Surg 1993;80:799-801

94 Schantz EJ. Historical perpective. In: Jankovic J, Hallet M, eds. Therapy with botulinum toxin. New York: Marcel Dekker Inc., 1994:xxiii-xxvi.

5 Scott AB. Botulinum toxin injection into extraocular muscles as an alternative to strabismus surgery. Ophthalmology 1980;87:1044-9.

96 Schiano TD, Parkman HP, Miller LS, et al. Use of botulinum toxin in the treatment of achalasia. Dig Dis 1998;16:14-22.
97 Jost WH, Schimrigk K. Use of botulinum toxin in anal fissure (letter). Dis Colon Rectum 1993:36:974.

98 Jost WH, Schimrigk K. Therapy of anal fissure using botulin toxin (see comments). Dis Colon Rectum 1994;37:1321-4.

99 Jost WH, Schimrigk K. Botulinum toxin in therapy of anal fissure. Lancet 1995;345:188-9.

100 Jost WH, Mlitz H, Schanne S, Schimrigk K. Botulinum toxin in the treatment of fissure-in-ano. Coloproct 1995;17:224-9.

101 Jost WH. One hundred cases of anal fissure treated with botulin toxin: early and long-term results (see comments). Dis Colon Rectum 1997;40:1029-32.

102 Espi A, Melo F, Minguez M, et al. Therapeutic use of botulinum toxin in anal fissures. Int $\mathrm{f}$ Colorectal Dis 1998;12:163.

103 Gui D, Cassetta E, Anastasio G, et al. Botulinum toxin for chronic anal fissure (see comments). Lancet 1994;344:1127-8.

104 Maria G, Cassetta E, Gui D, et al. A comparison of botulinum toxin and saline for the treatment of chronic anal fissure (see comments). $N$ Engl f Med 1998;338:217-20.

105 Jost WH, Schrank B. Chronic anal fissures treated with botulinum toxin injections: a dose-finding study with Dysport. Colorectal Dis 1999;1:26-8.

106 Delvaux M, Wingate D. Trimebutine: mechanism of action, effects on gastrointestinal function and clinical results. F Int Med Res 1997;25:22546.

107 Schaffstein W, Panijel M, Lüttecke K. Comparative safety and efficacy of trimebutine vans mebeverine in the treatment of irritable bowel trimebutine versus mebeverine in the
syndrome. Curr Ther Res 1990;47:136-45.

108 Ho YH, Seow-Choen F, Low JY, Tan M, Leong AP. Randomized controlled trial of trimebutine (anal sphincter relaxant) for pain after haemorrhoidectomy. Br F Surg 1997;84:377-9.

109 Pitt J, Boulos PB. Chemical sphincterotomy for anal fissure. Colorectal Dis 1999;1:2-8. 